\title{
Cold acclimatization in hairless mice measured by behavioral thermoregulation
}

SAMUEL H. REVUSKY

BIOPHYSICS DIVISION, U.S. ARMY MEDICAL RESEARCH LABORATORY, FORT KNOX, KENTUCKY

For 30 successive days, mice were administered six-hour periods in the cold $\left(48^{\circ} \mathrm{F}\right)$ and permitted to switch on a heat lamp by means of a free operant response. In the course of this training, the magnitude of the fall in skin temperature in the course of a session declined. The frequency of heat rewards also declined, indicating the development of cold acclimatization.

Behavioral thermoregulation refers to behaviors by which animals change the temperatures of their external environments. Its experimental analysis has usually consisted of allowing animals in a cold environment to activate a heat lamp by means of a free operant response. That the amount of extermal heat the animal will earn is an indirect measure of its susceptibility to cold is supported by experiments utilizing starvation, thyroidectomy, and pantothenic acid deficiency (Weiss \& Laties, 1961); these treatments increase the probability that animals will die during cold exposure and also increase the number of rewards animals will earn in a behavioral thermoregulation experiment.

Cold acclimatization may be defined as a decreased susceptibility to cold as a result of previous exposure to the cold (Sellers, 1957). As might be expected, previously cold acclimatized rats earn fewer heat rewards in an initial session of behavioral thermoregulation than nonacclimatized controls (Laties \& Weiss, 1960). It is known that mice (Nagy, 1966), as well as rats (Fregly, 1953) will acclimatize under conditions of intermittent exposure to cold; that is, during subsequent cold exposure, they will be able to maintain their body temperature at a higher level. The present experiment uses behavioral thermoregulation to chart the course of intermittent acclimatization in the USAMRL hairless mouse (Parr, 1957) under conditions in which it receives one daily 6-hr. exposure to the cold.

Method

The Ss were 39 male USAMRL hairless mice between 6 and 12 months of age at the beginning of the experiment.

Figure 1 is a picture of the test cage used with a $S$ in it. Its inside dimensions were 4.5 in. $x 2$ in. $x 1.5$ in. Three sides of the cage were constructed of wire mesh. The fourth side was constructed of Plexiglas with a panel of conductive rubber in its center. The floor was also constructed of conductive rubber so that a drinkometer circuit could detect whether the animal is in contact with the front panel. An infra-red heat lamp (not shown), $250 \mathrm{w}$, faced the end of the cage opposite the rubber panel; it was $2 \mathrm{in}$. from the cage at its closest point resulting in an intense burst of heat when activated. Twelve such units were maintained in a walk-in refrigerator maintained at $48^{\circ} \mathrm{F}$.

The mice were trained in this apparatus for $6 \mathrm{hr}$. daily for 30 successive days under conditions in which any contact with the front panel illuminated the heat lamp for 5 sec.; responses which began while the heat lamp was on were ineffective. Before and after each. session, the mice were weighed and their temperatures were taken on the rib cage under the right foreleg (sub-axilla temperature). In preliminary work, it was found that temperatures at this location correlated highly with rectal temperatures, although, of course, they were lower. Obtaining rectal temperatures proved too stressful to the Ss and experimenters to be worthwhile.

When the mice were not being trained, they were maintained in individual glass cages with free access to mouse chow, evaporated milk, and water. The temperature of the vivarium was $76-78^{\circ} \mathrm{F}$.

\section{Results and Discussion}

Figure 2 shows mean changes for the 39 mice over the course of the 30 sessions in terms of three measures: loss of sub-axilla temperature in the course of the session, heat rewards earned per hour, and body weight prior to the session $(p<.005$ for each effect shown; sign test between days 1-10 and 21-30). This is the presumed meaning of Fig. 2. The reduction in temperature loss in the course of the experiment indicates adaptation to the cold. That this reduction occurred in spite of a reduction in the number of heat rewards earned indicates that the adaptation was physiological in nature. The temperature loss curve seems to change in tandem with the rewards/hr. curve as follows. During days 1-12, temperature loss declines and subsequently remains constant; after day 12, rewards/hr., which had

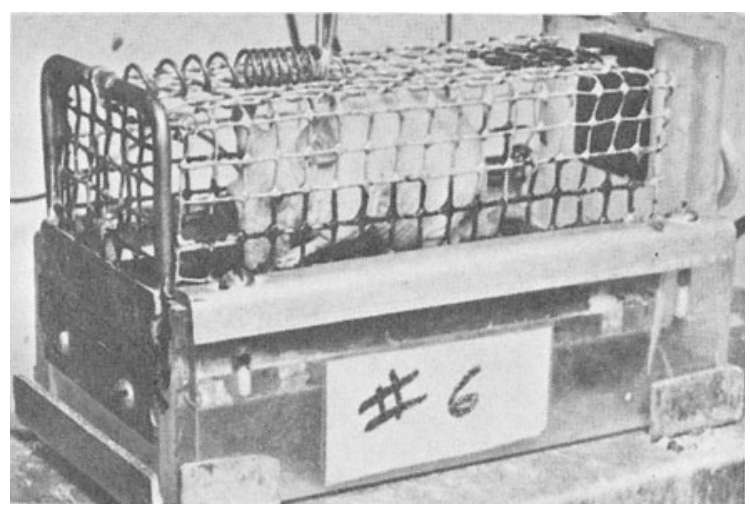

Fig. 1. A subject in the experimental apparatus. 


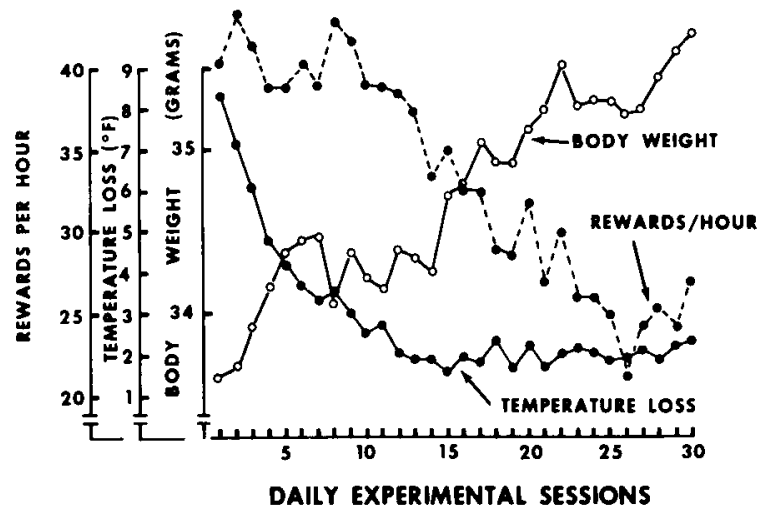

Fig. 2. The course of acclimatization.

previously remained roughly constant, began to decrease until about day 25. Thus it is reasonable to suppose that acclimatization continued throughout the first 25 days.

The increase in body weight shown in Fig. 2 almost certainly indicates that cold exposure increased the food intake of the mice, since the mice used were actults and could not reasonably have been expected to show such a marked increase under control conditions. It is known that animals will eat more after exposure to cold (Sellers, 1957). Thus the weight gains corroborate the general picture of acclimatization. The increased weight by itself may help preserve body heat, but this is a minor factor at most because, under more severe cold conditions than used in the present experiment, acclimatized animals are likely to weigh less than controls despite their increased food intake (Sellers, 1957).

It was the original purpose of this study to disrupt acclimatization by means of exposure to $\mathrm{X}$-irradiation after day 30 of training. It is known that sublethal doses of X-rays increase the probability that animals exposed to the cold will die (Newsom \& Kimeldorf, 1961), but since the measure of susceptibility to cold is death, it is difficult to trace out a subsequent decrease in susceptibility. It was felt that behavioral thermoregulation would eliminate this problem by allowing the animal to increase its environmental temperature during the period of maximum susceptibility. Unfortunately, no reliable changes in thermoregulatory behavior were obtained at 160 or 320 rof penetrating $X$-rays, where $500 \mathrm{r}$ is the LD-50 for these animals (Parr, 1957). At $640 \mathrm{r}$, there was an increase in the rate at which heat rewards were obtained, but the mice died shortly thereafter. Despite this failure to map changes in susceptibility to cold exposure as a function of time since sublethal irradiation, similar techniques may prove useful for other stressors.

\section{References}

Fregly, M. J. Minimal exposures needed to acclimatize rats to cold. Amer. J. Physiol., 1953, 173, 393-402.

Laties, V. G., \& Weiss, B. Behavior in the cold after acclimatization. Science, 1960, 131, 1891-1892.

Nagv, Z. M. Adaptation and persistence of adaptation to a cold suressor mice. Psychon. Sci., 1966, 4, 321-322.

Newsom, B. D., \& Kimeldorf, D. J. The resistance of animals to acute cold exposure following $\mathrm{x}$-irradiation. Int. J. Rad. Biol., $1961,4,143-149$.

Parr, W. Characteristics of the USAMRL hairless mouse and its heterozygote. USAMRL Report, 1957, 297, 1-24.

Sellers, E. A. Adaptive and related phenomena in rats exposed to cold; a review. Rev. Canad. Biol., 1957, 16, 175-188.

Weiss, B., \& Laties, V. G. Behavioral thermoregulation. Science, $1961,133,1338-1344$. 